مجلة سيناء لعلوم الرياضة_كلية التربية الرياضية ـ جامعة العريش- المجلد الثني- العدد الثاني-ديسمبر (2017) 451-464

مجلت سيناء لعلوم الرياضش:

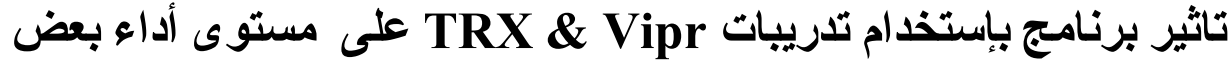

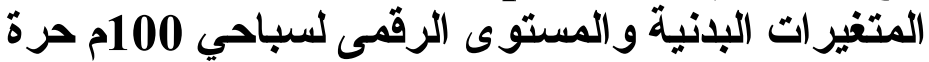

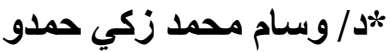

الملخص

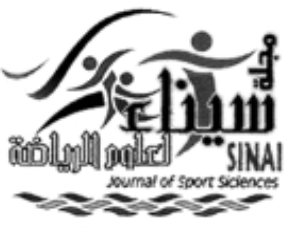

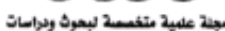

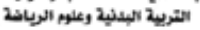

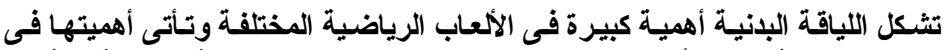

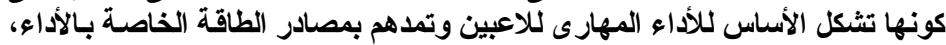

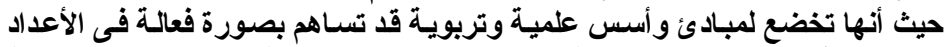

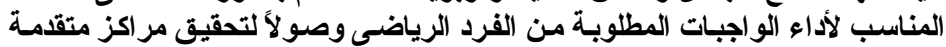

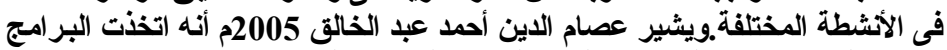

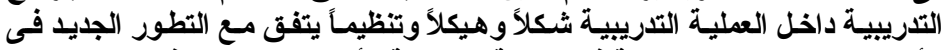

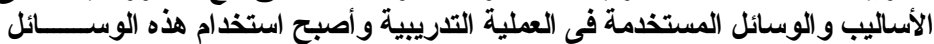

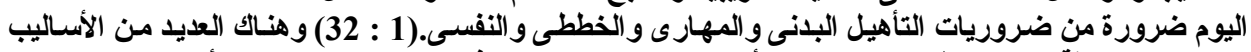

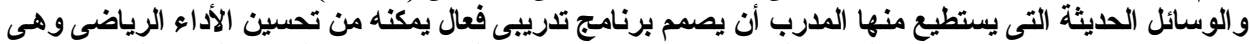

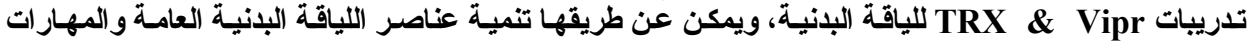

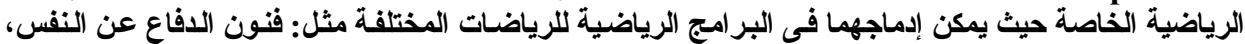

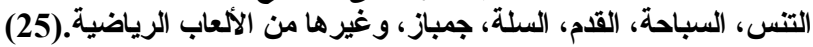

المستوى البدنى و المهارى للاعبـى الجمبـاز

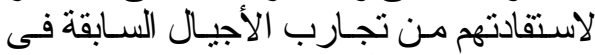

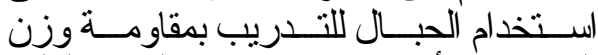
الجسم، ونشأت تدربيات مقاومة الجسم الكلية أو تدريبات التعلق TRX التى نعرفها اليوم

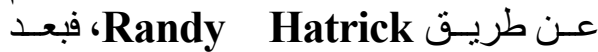

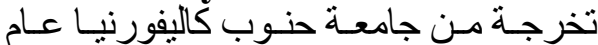
1987م قضـى 14 عام كقائد للقو ات الخاصنة

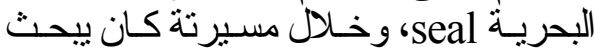

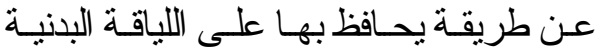

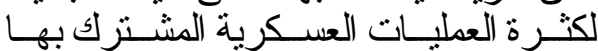

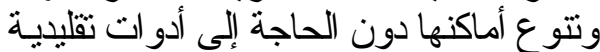
يحملها معه.

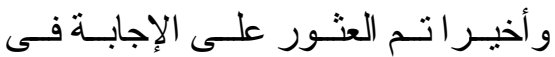

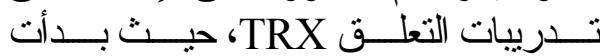

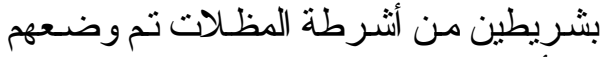
مع أدو ات إصلاح القو ارب المطاطية لتصبح

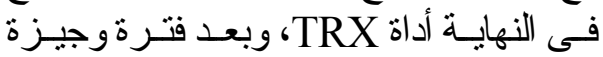

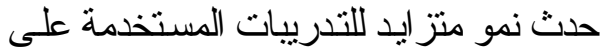
تنلك الأداة. (20 : 66، 67)

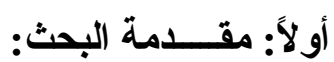

تعتمـد تـدريبات TRX علـى اسـتخدام وزن الجسم لتطوير القوة و القدرة و التحمـل التحل

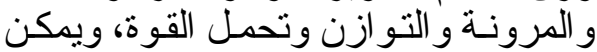

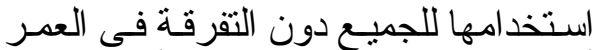

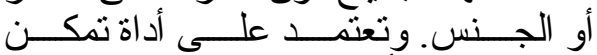

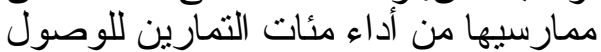
لأى هدف من أهداف اللياقة البدنية. (24)

Wesley D. Dudgeon all يذكر

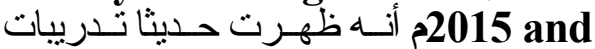
تعرف باسم "تدريبات مقاومة الجسـم الكلية "Total Body Resistance

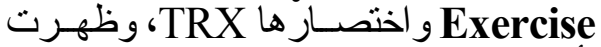
بأثكال مختلفة من مئات السنين في الوحدات

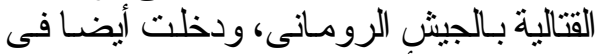

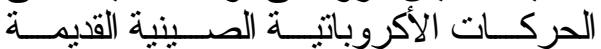

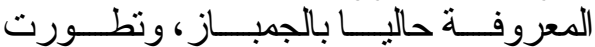

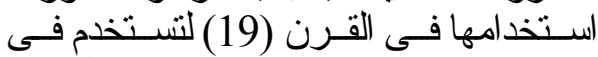

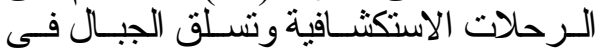

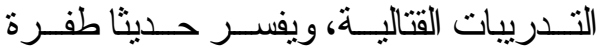


وتتمى جميع العناصر من خلال أداة واحدة فقط تعمل على تدريب العضلات الصنيرة الصنيرة

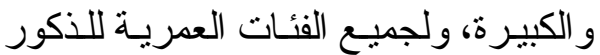

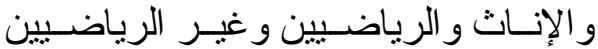

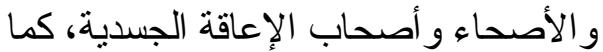

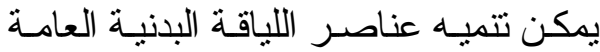

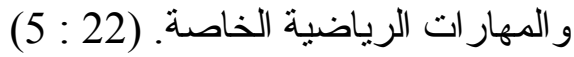

وتعتمـد تـدريبات TRX على اسـتخدام

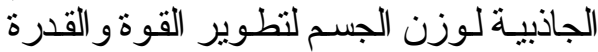

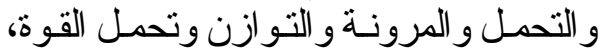

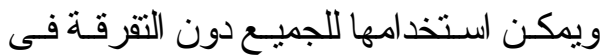

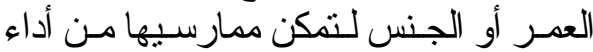

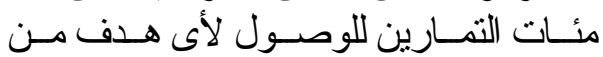

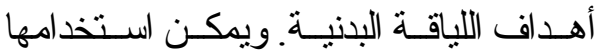
بطرق منتو عة، ويمكن تعديلها طبقا لصفات

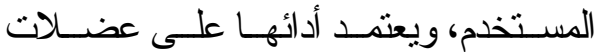

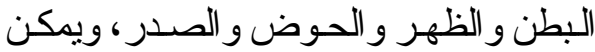
أيضا إضافة جاكت اثقال لزيـادة وزن الجسم

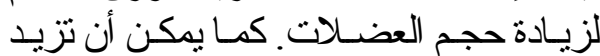

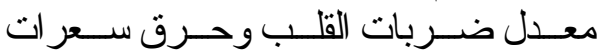
حر اريـة عاليـة أكثر مـن الوقـوف و الجلـوس

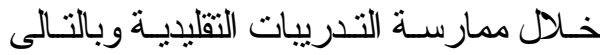

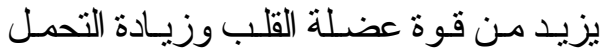
العضلى.(27) (25) (28) (25)

ويثــير "تـــومى بـــاو " أن اسـتخدام

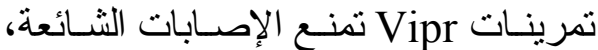

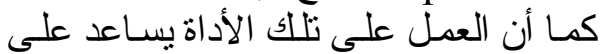

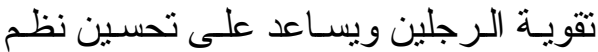

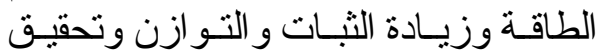

أقصى نمو للعضلات. (27)

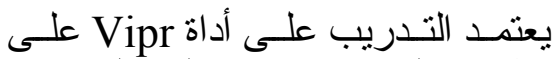

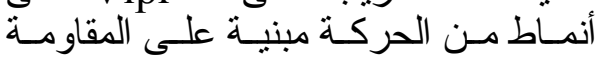

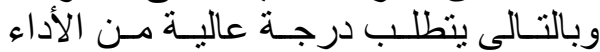

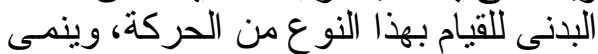

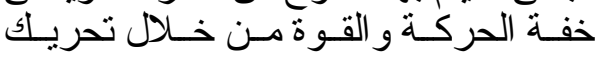

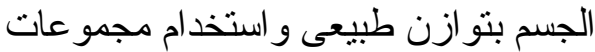
عضلية متعددة فى وقت و احد. (30)
ويشَير 2011 Lukáš Sláma إلى

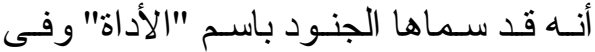

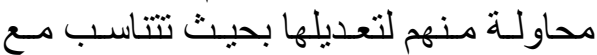

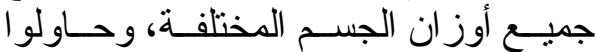
إيجاد نقطة لربطها فوجدو أنه يمكن تعليقها فى الأبو اب أو خز انات الميباة أو السيار ات الجيب. (12 :

Bc. Martin ويوضـح كـلا مسن

Martin Tůma ،2010 Hajnovič

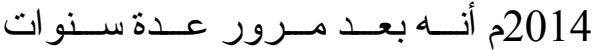
أصبحت أداة TRX مس الأدو الد ات الأساسية فى تدريب القوات المسلحة ومر اكز اللياقة التحنة

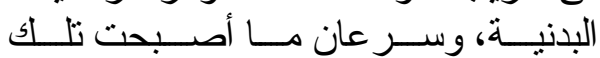

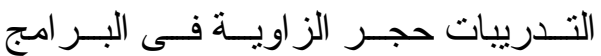

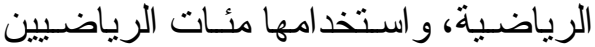

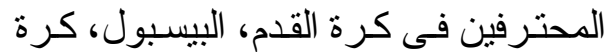

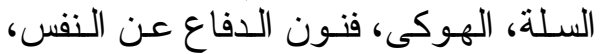

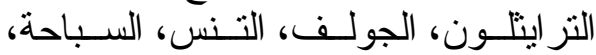

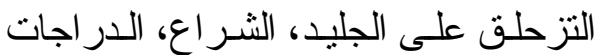

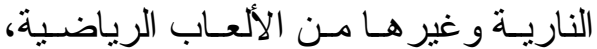

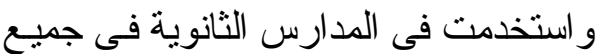

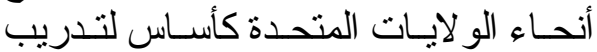
اللياقة البدنية. (15 : 19) (17 : 18) ويشبر 2010 Michael Miranda فى أن الأداة المستخدمة فى نظـام تدريبات

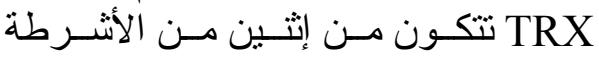

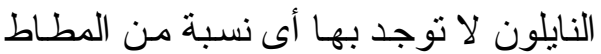

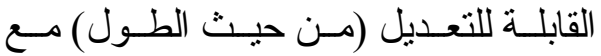
مقابض مبطنة وحمالات للقدم تعلق فى كل

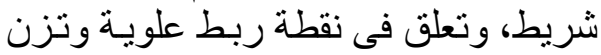

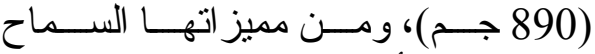

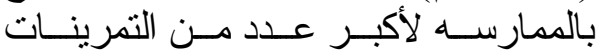

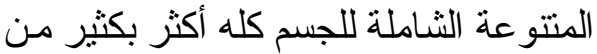

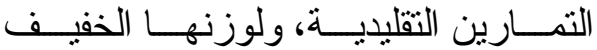

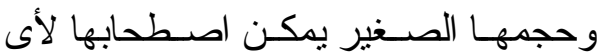

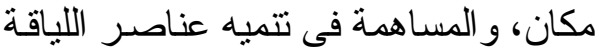
البدنية دون الحاجة إلى أى أجهزة فئهئ أخرى، 


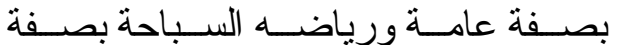
خاصة، و هذا مـا أثنار اهتمـام الباحثت للقيـام

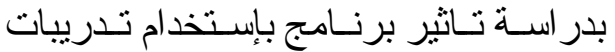
TRX \& Vipr المتغير ات البدنية و المستوى الرقمى لسباحي 100 هدف البحث:

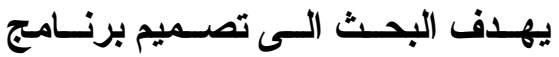

TRX \& مقترح باسـتخدام تـدريبات Vipr

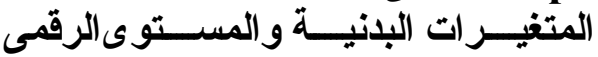
لسباحي 100م حرة للتعرف على: 1. تــأثير اســتخدام البرنـــامج التــدربيـي

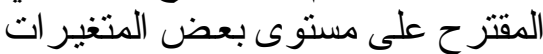
البدنية لسباحي 100متر حرة.

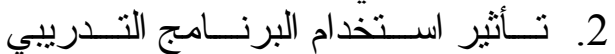
المقتر ح على تحسين المستوى الرقمي لـئي لسباحي 100منز حرة. ثالثاً: فروض البحث. 1. توجد فروق دالة إحصائيا بين القياسين

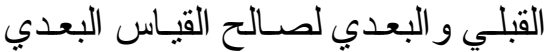

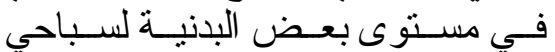

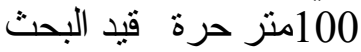
2. توجد فروق دالة إحصـيائيا بين القياسبين القبلي و البعدي لصالح القياس البعدي في في البياني المستوى الرقمي لسباحي 100منز حرة.

$$
\text { رابعا مصطلحات البحث: }
$$

1- تـدريبات Total ) TRX : Resistance Exercise

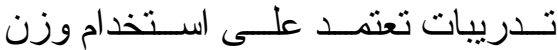

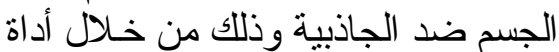
معلقة عبـارة عن شريطين من النـايلون

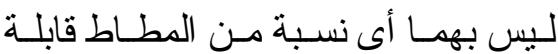

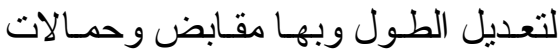

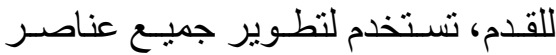

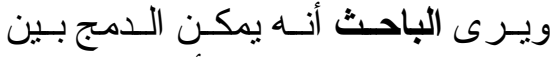
تدريبات TRX \& Vipr للأسباب التالية: ـ تعتبر تلك التدريبات أداء ممتعـا وتحديا

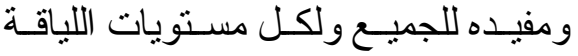
البدنية.

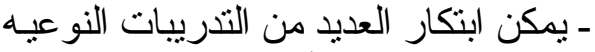

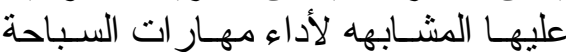
لتحسين الحالة البدنية و المهاريه. ـ تعتبر تلك التدريبات برنـامج كامل للياقة

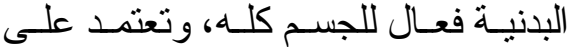

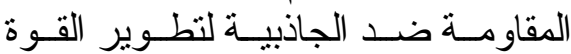

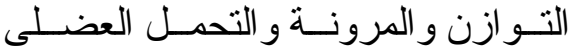
و القدرة و الرشاقة.

ـ يمكن استخدام هذه التدريبات لسد الفجوة

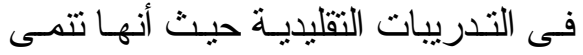
القوة مع الرشاقة. ثانياً : مشكلة البحث

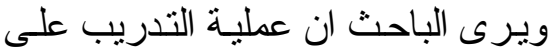
الصفات البدنية منفصلة يعمل على تدريب

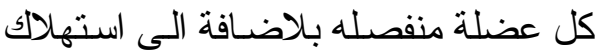

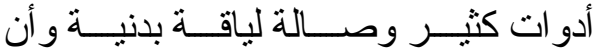

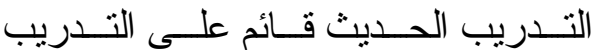

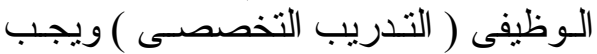
أن يكون التدريب الرياضـى للسباحة يعمل التهل على دمـج العضــلات العاملـة في السـباحة الحرة حتى يمتلك اللاعب نسبا معينـة من العن المتطلبات المختلفة لتلك الرياضة.

ومن خلال ما قام به الباحث من قر اءات نظرية ومسح مرجعى للار اسـات و الأبحاث

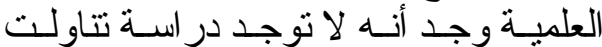
تدريبات TRX \& Vipr ف في رياضـة

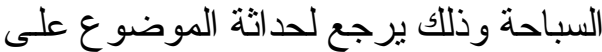

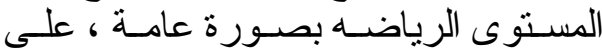
الر غم من أهميته فى تطوير القدر ات البدنيه

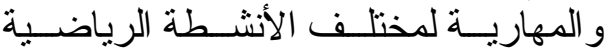


لعينة البحث الأساسية قد تر اوحت مـا بين

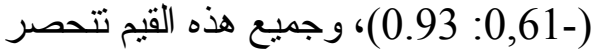

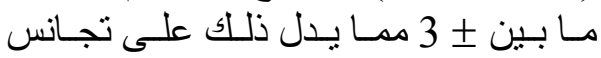
أفر اد عينة البحث في تلاك المتغير ات

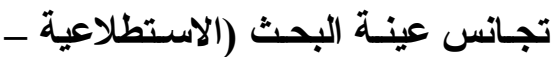

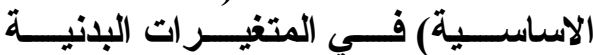
والمستوى الرقمي لسباحة 100 متر حرة الإني قيد البحث:

بتضح من جدول (2) أن قيم معاملات

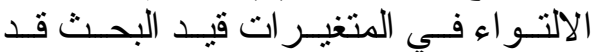

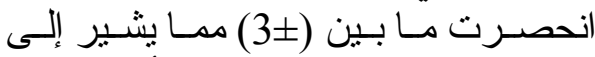
اعتدالية توزيع العينة، وتجانس أفر اد عينة البحث فى هذه المتغير اته وسائل وأدوات جمع البيانات:

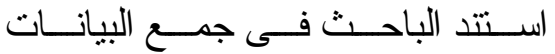

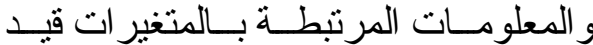

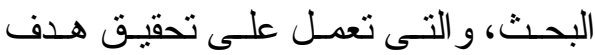
البحث إلى الأدوات التالية:

\section{المسح المرجعى:}

قـام الباحث في حدود مـا توصـل إلبـه

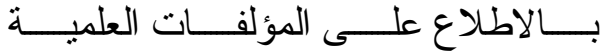

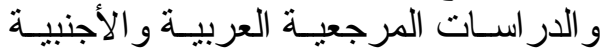

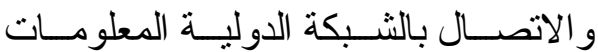
بهذف التعرف على:

\section{بناء الإطار النظرى المحقق لهدف البحث:}

تحديد تدريبات TRX \& Vipr التى

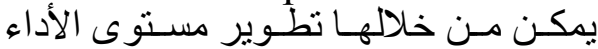

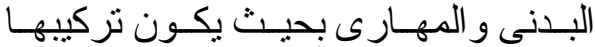

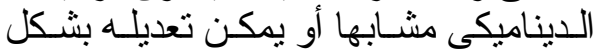

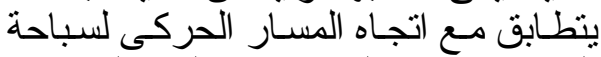

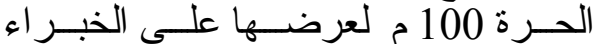

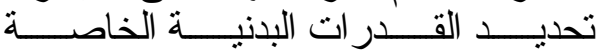

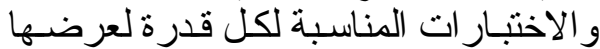
على الخبر اء ألخاء أت

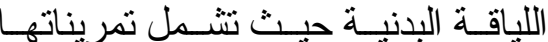

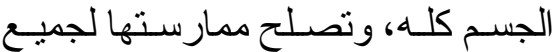

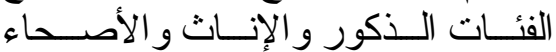

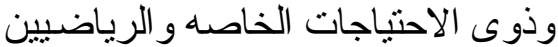
و غير الرياضيين. (تعريف إجرائى)

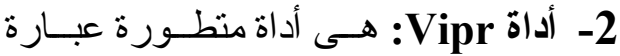

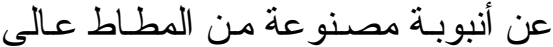

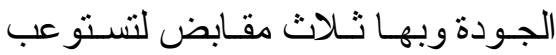

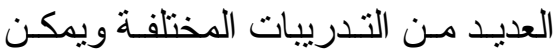

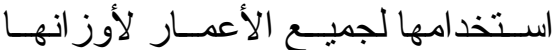

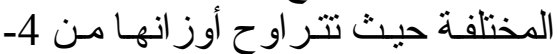
26 كجم، وتستخدم فى تحسين عناصر

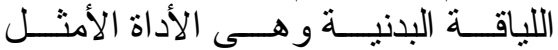

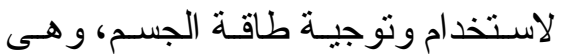

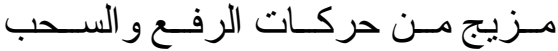

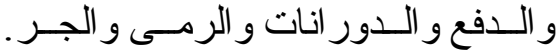
(تعريف إجرائى) منهج البحث:

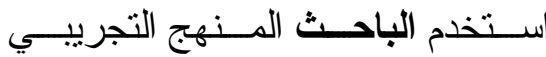
لملائمة لطبيعة هذا البحث و اعتمد الباحثث

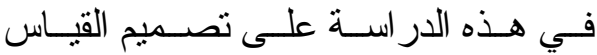
(القبلي البعدي) لمجمو عة و احدة تجريبية

\section{مجتمع وعينة البحث:}

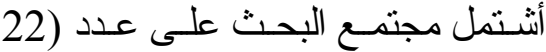

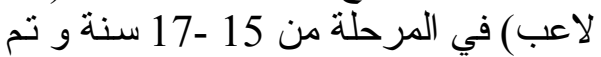
اختيـار هم بالطريقـة العمديـة مـن أكاديمبـة

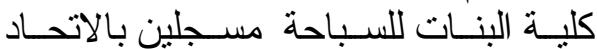

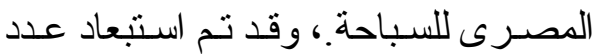

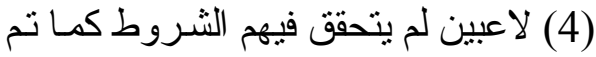

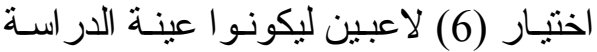

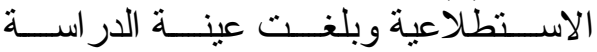
الاسـاسية (12) لاعبين.

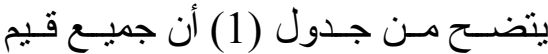

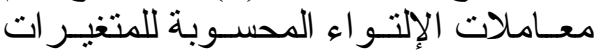

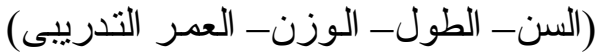


جدول (1): التوصيف الإحصائى لقياسات المتغيرات الأساسية ن = 16

\begin{tabular}{|c|c|c|c|c|c|c|}
\hline معامل الإلتواء & الإنعيارى افى & | الوسيط | & المتوسط & وحدة القياس & المتغير ات & العينة \\
\hline 0.05 & 0.75 & 16 & 16.22 & سنة & السن & \multirow{4}{*}{ أعلية التينة البحثية } \\
\hline 0.61 - & 5.78 & 167.50 & 167.60 & 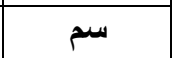 & الطول & \\
\hline 0.93 & 5.78 & 66 & 67.40 & كجم & الوزن & \\
\hline 0.55 & 0.96 & 9 & 10.92 & سنة & العمر التدريبى & \\
\hline
\end{tabular}

جدول (2): المتوسط الحسـابي و الوسيط و الاتحر اف المعيـاري ومعامـل الاتتواء لعينـة البحث (في المتغيرات قيل البحث ن= 18

\begin{tabular}{|c|c|c|c|c|c|c|}
\hline | & | الاحعراف & الوسيط & المستوسي & القياس & الاختبارات & المتغير ات \\
\hline .523 & 1.36626 & 62.0000 & 62.3333 & ثانية & اختبار جرى 400 م & \multirow{10}{*}{ 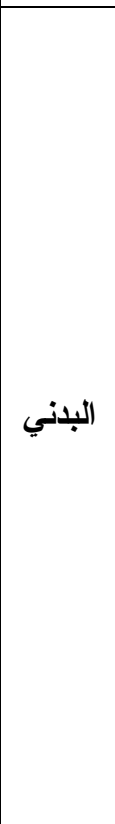 } \\
\hline $\begin{array}{l}.968 \\
\end{array}$ & .51640 & 24.0000 & 23.6667 & درجة & اختبار تحمل السرعة للسباحين & \\
\hline .723 & 1.86190 & 30.0000 & 30.6667 & عدد & اختبار ثني الذراعين من الآبطاح | المائل & \\
\hline .811 & 3.44480 & 39.0000 & $\mathbf{3 9 . 3 3 3 3}$ & عدد & اختبار الجلوسن من الرقود (ثنى & \\
\hline-.271 & 5.41910 & 177.5000 & 177.8333 & متز & |ختبار الوثب العريض من الثبات & \\
\hline-1.166 & 1.96638 & 26.0000 & 25.3333 & علد & اختبار اليوروبى & \\
\hline 0.25 & 2.17 & 38 & 38.30 & كجم & قوة القبضة لليا المفضلة & \\
\hline 1.23 & 3.47 & 133 & 133.80 & كجم & قوة عضلات الظهر بالايناموميتر & \\
\hline 0.64 & 5.28 & 137 & 139 & كجم & قوة عضلات الرجلين بالايناموميتر | & \\
\hline $0.90-$ & 0.91 & 12 & 12 & عدد/ث & ثنى الأزراعين كاملا من الأبطاح & \\
\hline-.046 & .77717 & 58.1000 & $\mathbf{5 7 . 9 0 0 0}$ & ثانية & 100 متر حرة & |الرقيتوى |لمي | \\
\hline
\end{tabular}




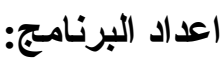

الار اسة الاستطلاعية:

الأهدف الرئيسي للبرنامج:

التعرف على تـاثير برنـامج بإستـخدام

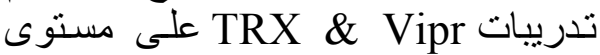

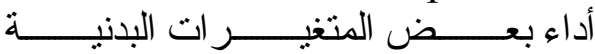

و المستوى الرقمى لسباحي 100م حرة.

معايير البرنامج التدريبي: • مرونة البرنامج وقابليتيه للتعديل.

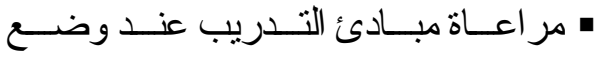

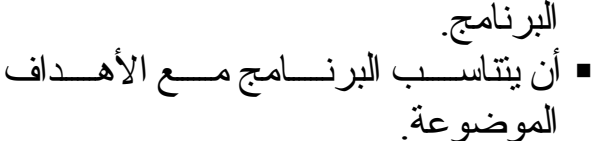

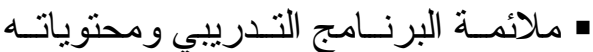
للامرحلة السنية للعينة المختارة.

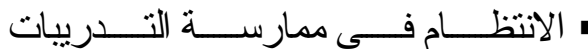
الموضـو عة بالبرنـامج حتى يعود بالفائدة المرجوة. • مر اعاة أن يكون أداء المهار ات و التدريب عليها في شكل تدرييات السباحة.

محسدات البرنــامج التــريبي: محتويـات

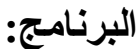

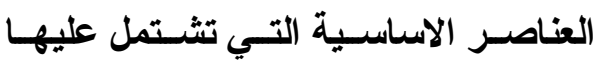
الوحدة التدريبية بالبرنامج التدريبي هي: 1. الجزء التمهيدي (فترة الاحماء):

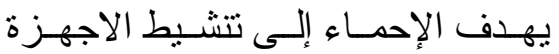

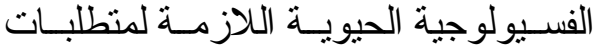
نشاط الجسم.

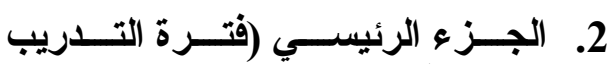
الاستاسية) ويشمل على: الرنسي

ـ التـدريب المهـارى: أداء سبـاحة 100 متر حرة.

• تـدريبات TRX \& Vipr : برياضة السباحة لسباحي 100 متر حرة.
الاراسة الاستطلاعية الاولى من الفترة من 2017/6/1 م الى الفترة 2017/6/13

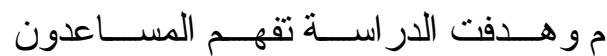
واللاعبين لمفاهيم تدريبات Vipr

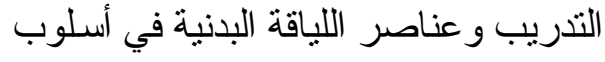

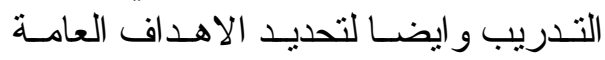
للبرنامج ومو عد تتفيذ البرنامج قيد البحث. حساب المعاملات العلمية للاختبارات: قـام الباحث باختبـار عينـة استطلاعبة لاعنية من مجتمع البحث وقو امها (6) لاعبيا لاعبين من البن

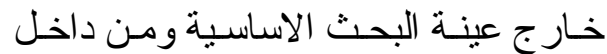

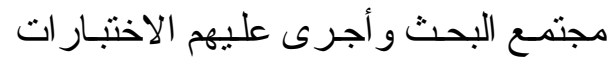

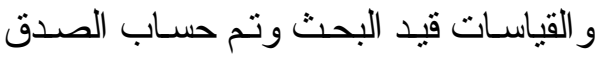
و الثبات للاختبار ات المستخدمة كالتالي: صدق الاختبار ات

يتضـح مسن جدول (17) وجود فروق

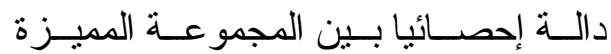

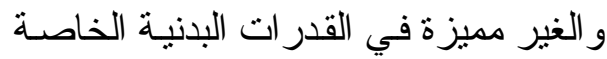
قبد البحث حيث قيمة " z " المحسوبة أكبر الفير

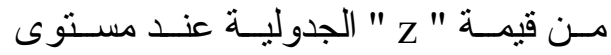

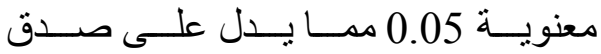
الاختبار ات قيد البحث

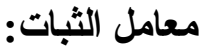

يتضـح مـن جدول (4) وجـود ارتبـاط معنوي عند مسنتوى معنويـة (4,05) حيث

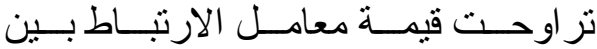

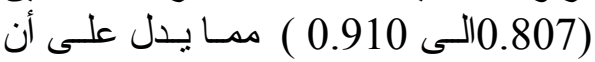
الاختبـار ات على درجـة عاليـة مـن الثبـات وبالتالي تصلح للاستخدام . 
3. الجزء الختامي (فترة التهائة): العودة تطبيق البرنامج:

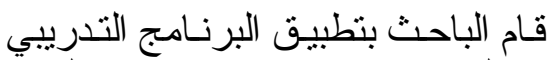

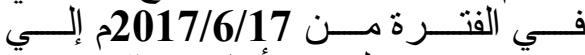

و 2017/8/17 ولمدة 8 أسابيع بو اقع خمس الانس

إلى الحالة الفسيولوجية الطبيعية

وحدات تدرييية في الاسبو ع.

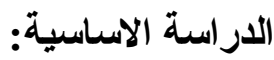

القياسات البعدية:

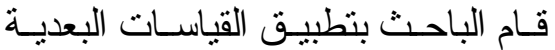

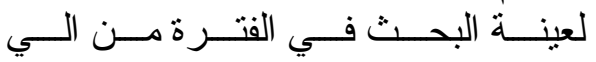

2017/8/18 إلى 2017/8/20

المعالجات الإحصائية:

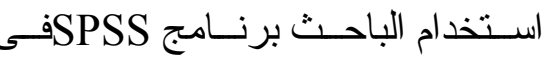

المعالجات الإحصائية المناسبة للبحث . لـاهي

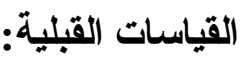

ـ قــام الباحـث بتطبيـق القياســات القبليـة

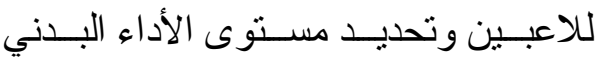

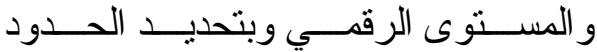
القصوى للتنريبات المستخدمة وذللك لتقنين الحمل التدريبي وتطبيق مبدأ الفرديـة في لفي التنريب.في الفترة من 2017/6/14م إلي

.2017/6/15

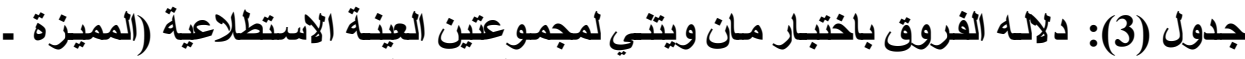

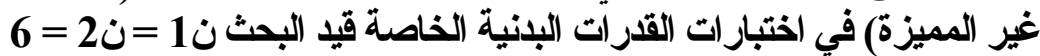

\begin{tabular}{|c|c|c|c|c|c|c|c|}
\hline أحتمال & قيمة "ذ " "ق & 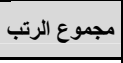 & متوسط الرتب & 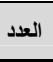 & المجموعة & المتغيرات & 个 \\
\hline \multirow{3}{*}{.003} & \multirow{3}{*}{1.994} & 57.00 & 9.50 & 6 & المميزة & \multirow{3}{*}{ إختبار جرى 400 م } & \multirow{3}{*}{-1} \\
\hline & & 21.00 & 3.50 & 6 & غير المميزة & & \\
\hline & & & & 12 & 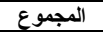 & & \\
\hline \multirow{3}{*}{.003} & \multirow{3}{*}{2.920} & 56.00 & 9.33 & 6 & المميزة الميزة & \multirow{3}{*}{ إختبار تحمل السرعة للسباحين } & \multirow{3}{*}{-2} \\
\hline & & 22.00 & 3.67 & 6 & غير الميزة & & \\
\hline & & & & 12 & 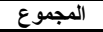 & & \\
\hline \multirow{3}{*}{.005} & \multirow{3}{*}{2.122} & 57.00 & 9.50 & 6 & الم الميزة & \multirow{3}{*}{ إختبار ثني الذراعين من الابططاح المائل } & \multirow{3}{*}{-3} \\
\hline & & 21.00 & 3.50 & 6 & غير الميزة & & \\
\hline & & & & 12 & 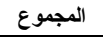 & & \\
\hline \multirow{3}{*}{.041} & \multirow{3}{*}{2.244} & 51.50 & 8.58 & 6 & المميزة & \multirow{3}{*}{ إختبار الجلوس من الرقود (ثنى الركبتين) " 30ث " } & \multirow{3}{*}{-4} \\
\hline & & 26.50 & 4.42 & 6 & غير المميزة & & \\
\hline & & & & 12 & 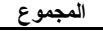 & & \\
\hline \multirow{3}{*}{.003} & \multirow{3}{*}{2.000} & 57.00 & 9.50 & 6 & الم الميزة & \multirow{3}{*}{ إختبار الوثب العريض من الثبات } & \multirow{3}{*}{-5} \\
\hline & & 21.00 & 3.50 & 6 & غير المميزة & & \\
\hline & & & & 12 & 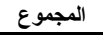 & & \\
\hline \multirow{3}{*}{.005} & \multirow{3}{*}{-2.738} & 55.00 & 9.17 & 6 & لم الميزة & \multirow{3}{*}{ إختبار اليوروبى } & \multirow{3}{*}{-6} \\
\hline & & 23.00 & 3.83 & 6 & غير الميزة & & \\
\hline & & & & 12 & 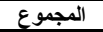 & & \\
\hline \multirow{3}{*}{.003} & \multirow{3}{*}{2.142} & 51.50 & 8.58 & 6 & الم الميزة & \multirow{3}{*}{ قوة القبضة لليد المفضلة بالمانوميتر } & \multirow{3}{*}{-8} \\
\hline & & 26.50 & 4.42 & 6 & غير الميزة & & \\
\hline & & & & 12 & 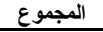 & & \\
\hline \multirow{3}{*}{.003} & \multirow{3}{*}{2.352} & 51.50 & 8.58 & 6 & المميزة & ق ق عضلات الظط بالاينامه مت & \\
\hline & & 26.50 & 4.42 & 6 & غير الميزة & 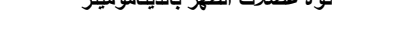 & -9 \\
\hline & & & & 12 & المجموع المجوع & & \\
\hline & & 51.50 & 8.58 & 6 & الم الميزة & 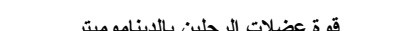 & \\
\hline .002 & 2.424 & 26.50 & 4.42 & 6 & غير الميزة & 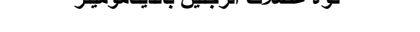 & -10 \\
\hline & & & & 12 & المجموع المجوع & & \\
\hline 01 & 2924 & 51.50 & 8.58 & 6 & الم الميزة & 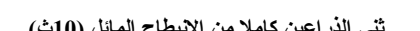 & \\
\hline .01 & $2.4 \angle 4$ & 26.50 & 4.42 & 6 & غير الميزة & 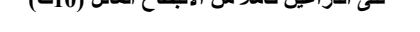 & -11 \\
\hline & & & & 12 & 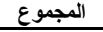 & & \\
\hline
\end{tabular}


تاثير برنامج بإستخدام تدريبات TRX \& Vipr على مستوى أداء بعض المتغيرات البذنية و والمستوى الرقمى لسباحي 100م عرة معنوم

جدول (4): معامل الارتباط بين التطبيقين (الأول ـ الثاني) لمتغير ات القدرات البذنية ن 6

\begin{tabular}{|c|c|c|c|c|c|c|}
\hline \multirow[t]{2}{*}{ معامل الارتباط } & \multicolumn{2}{|c|}{ التطبيق الثاني } & \multicolumn{2}{|c|}{ التطبيق الأول } & \multirow{2}{*}{ وحدة القياس } & \multirow{2}{*}{ الاختبارات } \\
\hline & الاححراف & المتوسط & الاححراف & المتوسط & & \\
\hline $.843 *$ & 1.37840 & 62.5000 & 1.36626 & 62.3333 & متز & إختبار جرى 400 م \\
\hline $.832 *$ & .40825 & 23.8333 & .51640 & 23.6667 & عدد /ث & إختبار تحمل السرعة للسباحين \\
\hline $.807 *$ & 2.04124 & 31.1667 & 1.86190 & 30.6667 & ثانية & إختبار ثني الذراعين من الأبطاح \\
\hline $.881 *$ & 3.03315 & 40.0000 & 3.44480 & $\mathbf{3 9 . 3 3 3 3}$ & ثانية & إختبار الجلوس من الرقود (ثنى " 30 " الركبن) \\
\hline $.976 *$ & 4.96655 & 177.3333 & 5.41910 & 177.8333 & عدد & إختبار الوثب العريض من الثبات \\
\hline $.910 *$ & 1.78885 & 25.0000 & 1.96638 & 25.3333 & سم & إختبار اليوروبى \\
\hline $.847 *$ & 1.33 & 29.30 & 1.63 & 42.70 & كجم & قوة القبضة لليا المفضلة \\
\hline $.934 *$ & 3.52 & 124.70 & 2.13 & 142.90 & كجم & قوة عضلات الظهر بالايناموميتر \\
\hline $.846 *$ & 4.69 & 135.50 & 2.21 & 144.70 & كجم & قوة عضلات الرجلين بالديناموميتر \\
\hline $.799 *$ & 0.52 & 8.50 & 0.73 & 14.10 & عدد/ث & ثنى الذراعين كاملا من الأبطاح \\
\hline
\end{tabular}

جدول (5)متغير ات البرنامج التدريبي

\begin{tabular}{|c|c|c|}
\hline الفترة & متغيرات البرنامج & 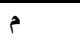 \\
\hline ثُلاثة أشهر (8) اسابيع & مدة البرنامج & .1 \\
\hline فترة الإعداد الخاص وقبل المنافسات & فترة التنفيذ & .2 \\
\hline ( 5 ) وحدات أسبوعيا & عدد الوحدات التّريبية فى الأسبوع & .3 \\
\hline$\% 10$ & نسبة الأحماء & .4 \\
\hline$\% 25$ & نسبة الجزء المهارى & .5 \\
\hline$\% 60$ & نسبة تدريبات TRX \& Vipr & .6 \\
\hline$\% 5$ & نسبة الجزء الختامى & .7 \\
\hline (40) وحده & عدد وحدات البرنامج & .8 \\
\hline 40 & عدد أيام التدريب & .9 \\
\hline (240ق) = (60 سناعة). & عدد سـاعات التّريب & .10 \\
\hline 60 دقيقة & زمن الوحدة التدريبية & .11 \\
\hline (85٪) حمل عالى & الثدة العامة للبرنامج & .12 \\
\hline (الفتري مرتفع ومنخفض الثدة ـ التكراري). & طرق التدريب المستخدمة & .13 \\
\hline
\end{tabular}


مجلة سيناء لعلوم الرياضة_كلية التربية الرياضية ـ جامعة العريشـ المجلد الثاني- العدد الثاني-ديسمبر (2017)

جدول (6): دلالة الفروق بين متوسط القياسيين (القبلى - البعدى) للمجموعة فى قياسات القدرات البذنية والمستوى الرقمى ن = 12

\begin{tabular}{|c|c|c|c|c|c|c|c|}
\hline أحتمال الخطأ & قيمة " ذ " & |مجموع الرتب & متوسط الرتب & العدد & الاتجاه & المتغيرات & 5 \\
\hline \multirow{4}{*}{002.} & \multirow{4}{*}{$* 3.064$} & 78.00 & 6.50 & 12 & - & \multirow{4}{*}{ إختبار جرى 400 م } & \multirow{4}{*}{-1} \\
\hline & & 0.00 & 0.00 & 0 & + & & \\
\hline & & & & 0 & $=$ & & \\
\hline & & & & 12 & المجموع & & \\
\hline \multirow{4}{*}{001.} & \multirow{4}{*}{$* 3.176$} & 78.00 & 6.50 & 12 & - & \multirow{4}{*}{ إختبار تحمل السرعة } & \multirow{4}{*}{-2} \\
\hline & & 0.00 & 0.00 & 0 & + & & \\
\hline & & & & 0 & $=$ & & \\
\hline & & & & 12 & المجموع & & \\
\hline \multirow{4}{*}{002.} & \multirow{4}{*}{$* 3.068$} & 0.00 & 0.00 & 0 & - & \multirow{4}{*}{ إختبار ثني الأر اعين } & \multirow{4}{*}{-3} \\
\hline & & 78.00 & 6.50 & 12 & + & & \\
\hline & & & & 0 & $=$ & & \\
\hline & & & & 12 & المجموع & & \\
\hline \multirow{4}{*}{002.} & \multirow{4}{*}{$* 3.063$} & 0.00 & 0.00 & 0 & - & \multirow{4}{*}{ الرقبار الجلوس من الركبتين) } & \multirow{4}{*}{-4} \\
\hline & & 78.00 & 6.50 & 12 & + & & \\
\hline & & & & 0 & $=$ & & \\
\hline & & & & 12 & المجموع & & \\
\hline \multirow{4}{*}{002.} & \multirow{4}{*}{$* 3.069$} & 0.00 & 0.00 & 0 & - & \multirow{4}{*}{ إختبار الوثب العريض } & \multirow{4}{*}{-5} \\
\hline & & 78.00 & 6.50 & 12 & + & & \\
\hline & & & & 0 & $=$ & & \\
\hline & & & & 12 & المجموع & & \\
\hline \multirow{4}{*}{.002} & \multirow{4}{*}{$* 3.078$} & 0.00 & 0.00 & 0 & - & \multirow{4}{*}{ إختبار اليوروبى } & \multirow{4}{*}{-6} \\
\hline & & 78.00 & 6.50 & 12 & + & & \\
\hline & & & & 0 & $=$ & & \\
\hline & & & & 12 & المجموع & & \\
\hline \multirow{4}{*}{.003} & & 78.00 & 6.50 & 0 & - & قوة القبضة لليد & \\
\hline & & 0.00 & 0.00 & 12 & + & المفضلة بالماتوميتر & \\
\hline & 2.462 & & & 0 & $=$ & قوة عضلات الظهر & -7 \\
\hline & & & & 12 & المجموع & ד" דים & \\
\hline & & 78.00 & 6.50 & 0 & - & & \\
\hline & 2625 & 0.00 & 0.00 & 12 & + & قوة عضلات الرجلين & 8 \\
\hline .003 & 2.635 & & & 0 & $=$ & بالايناموميتر & -8 \\
\hline & & & & 12 & المجموع & & \\
\hline & & 0.00 & 0.00 & 0 & - & & \\
\hline & & 78.00 & 6.50 & 12 & + & ثنى الأر اعين كاملا من & -9 \\
\hline .002 & 2.565 & & & 0 & $=$ & الآنبطاح المائل (10ث) & \\
\hline & & & & 12 & المجموع & & \\
\hline & & 0.00 & 0.00 & 0 & - & & \\
\hline .01 & 2.664 & 78.00 & 6.50 & 12 & + & المستوى الرقمي100 & -10 \\
\hline & & & & 0 & $=$ & مثر حرة & -10 \\
\hline & & & & 12 & المجموع & & \\
\hline
\end{tabular}


تاثير برنامج بإستخدام تدريبات TRX \& Vipr على مستوى أداء بعض المتغيرات البدنية

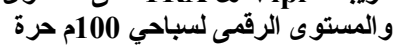

جدول (7): المتوسط الحسابي والاتحر اف المعياري لقياسـات البحث (القبلية ــ البعديـة) في متغير ات المتغير ات البدنية والمستوى الرقيطى قيد البحث ن = 12

\begin{tabular}{|c|c|c|c|c|c|c|c|}
\hline \multirow[b]{2}{*}{ معدل التغير } & \multicolumn{2}{|c|}{ القياس البعدى } & \multicolumn{2}{|c|}{ القياس القبلى } & \multirow[b]{2}{*}{ القياس } & \multirow[b]{2}{*}{ الاختبار ات } & \multirow{2}{*}{ المتغيرا } \\
\hline & الالمعياري & الحستوسطي & الالمعراري & المستوسطي & & & \\
\hline $12 \%$ & .72090 & 55.7833 & 1.38170 & 62.5000 & ثانية & | إختبار جرى 400 | & \\
\hline $7 \%$ & .07538 & 7.5250 & .07930 & 7.6917 & ثانية & 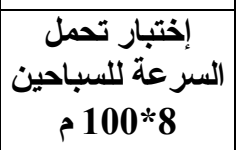 & \\
\hline $14 \%$ & 1.62135 & 35.4167 & 1.62135 & 30.4167 & عدد & الأختبار ثني الأبن من المبائل & \\
\hline $12 \%$ & 2.77843 & 44.5833 & 3.11764 & 39.4167 & عدد & 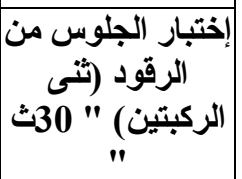 & \\
\hline $4 \%$ & 4.54189 & 184.4167 & 5.28219 & 177.0833 & |سنتيمتر & |العريض من الثبات الوثب & البذنى \\
\hline $18 \%$ & 1.05529 & 30.2500 & 2.00567 & 24.7500 & عدد & إختبار اليوروبى & \\
\hline$\% 16.36$ & 2.29 & 44.80 & 1.95 & 38.50 & 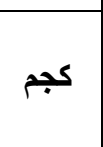 & قوة القبضة لليد & \\
\hline$\% 10.86$ & 0.84 & 148.50 & 3.62 & 133.50 & كجم & ققوة عضلات الظهر & \\
\hline$\% 9.79$ & 1.71 & 152.40 & 4.13 & 138.80 & 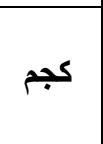 & قالدة عضلات & \\
\hline$\% 27.27$ & 0.51 & 15.40 & 0.99 & 12.10 & عدد/ث & 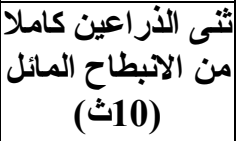 & \\
\hline$\% 6.28$ & .88763 & 54.6667 & .85635 & 58.0333 & ثانية & 100 متر حرة & الرقمى المستوى \\
\hline
\end{tabular}


شكل وطبيعة الأداء المهارى لنوع النشاط

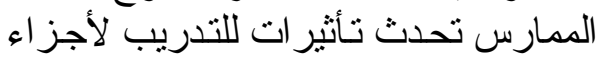
و أجهزة الجسم التى تقع مباشرة تأنحت تأنثر حمل التثريب. (1 : 35) (35)

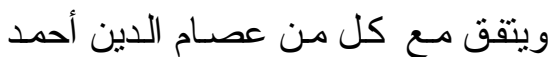

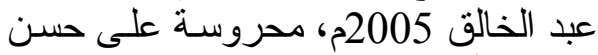

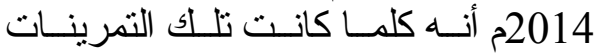

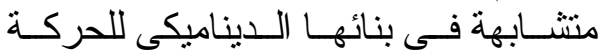
المر اد تعلمها كلما ز اد تعلم وتحسنت الأداء

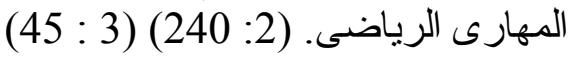

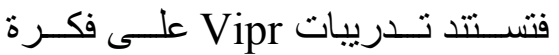

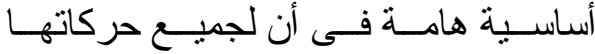

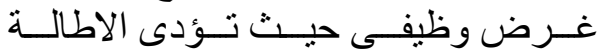
بالتقصير فى اتجاهات متعددة بحيث تشكي الاطن الأساس الوظيفى لها. (114) ويضــيف إلـى ذلـكـ نضــال فيصـل أبـو الفيلات 2013م أن تـدرييات Vipr مختلفــة فينة

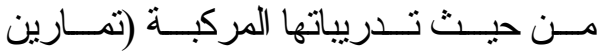

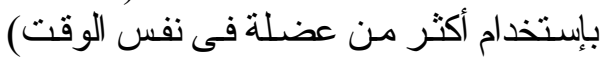
وتعمل على تحسين العمل الهو ائى وتحسين الفين

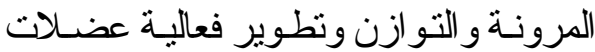

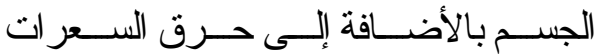

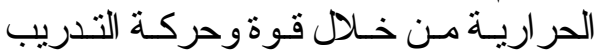

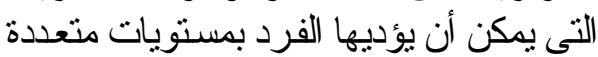

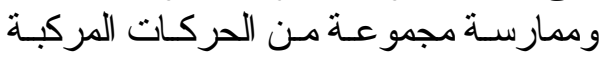
التى يمكن تأديتها. (6 : 10 1)

ويذكر 2011 Dannelly, and all

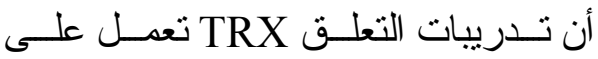

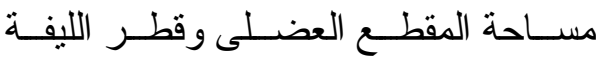

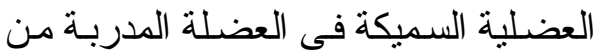

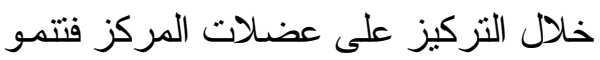

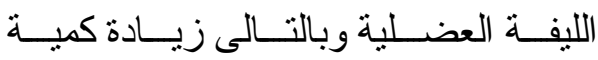
البروتين فـى العضـلات، الذى يؤدى غلى لكى اكتساب النغمة العضلية. (68 : 150)
عرض النتائج ومناقشتها: يتضـح مسن جدول (7) و الذي يظهـر

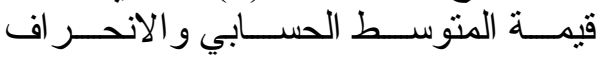

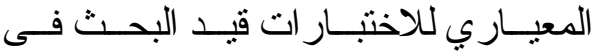
القياسين القبلى و البعدى لعينة البحث. ويرجع الباحث الفروق الدالة إحصـائيا،

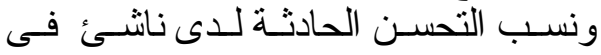

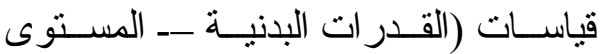
الرقمى) قيد البحث إلى : البدان ـ الأثر الايجابى للبرنامج التدريبى المقتر ح

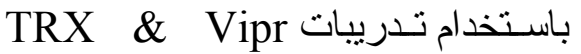

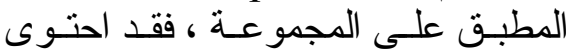

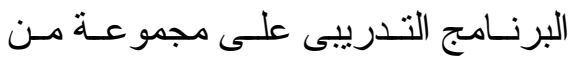

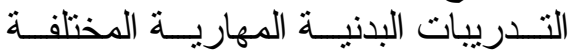

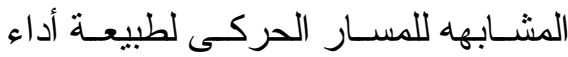

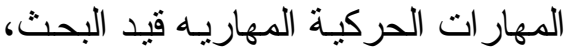
وتهدف إلى تطوير بعض القدر ات البدنية

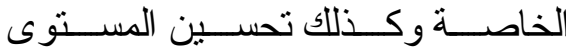

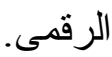

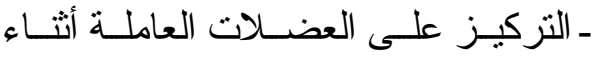
الأداء الحركى لسباق 100 منر حرة.

- دقة اختيار تدريبات

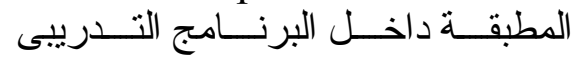

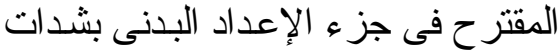

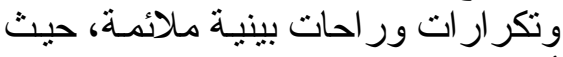

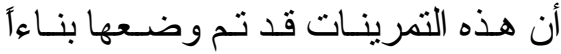

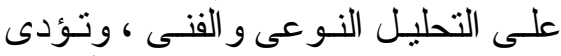

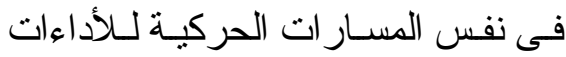
المهارية المختارة قبد البحث.

ـ مر اعـاه التـدر جهى الأحمــال التدريبيـة

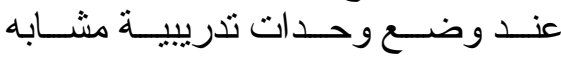
لظروف المنافسة.

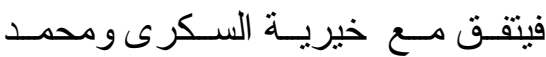

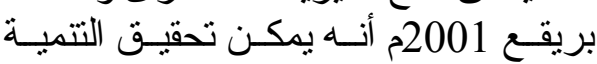
القصوى من التدريب إذا أخذت التمرينات 
وفى هذا الصدد يشير Burns Nick ت المراجع

خيرية السكرى، محمد بريقع: سلسلة التدريب المتكامل لصناعة البطل 6 - 18 سنة سلة،

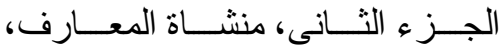
الإسكندرية، الئ 2001 م

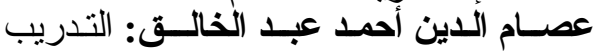

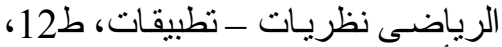
منشأة المعارف، الإسكندرية، 2005م.

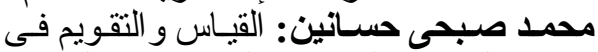

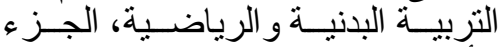

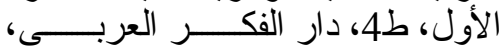

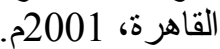

يم السيل الحساوى: المدرب الرياضسى بين الأسلوب التقليدى و التقنية الحديثة في لئى مجـال التـدريب، مركز الكتاب العربـى

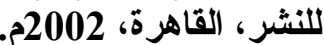

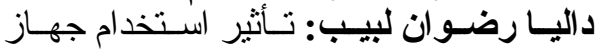

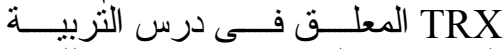

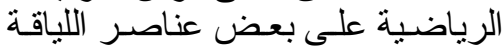

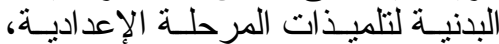

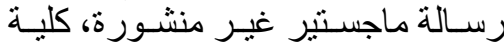

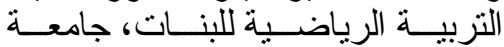
حلو ان، 2014م. 2014. مريم مصطفى محمد: تأثثر برنامج باستخدام

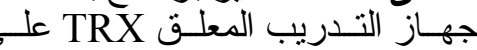

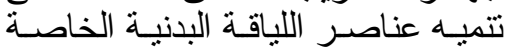
ببرض المهـار ات الهجوميـة للاعبـات

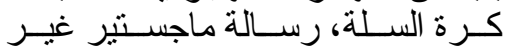

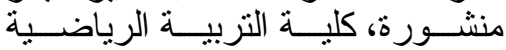

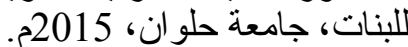
نضال فيصل أبو الفيلات: أثر برنـامج تدريبى

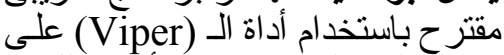

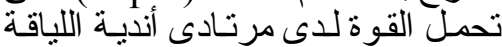

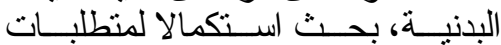

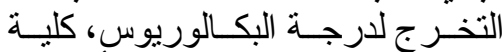
الثربيـة الرياضية، الجامعـة الأردنيـة، 2013. سـماح محمد عبد المعطى: فاعليـة أسلوب التدريب المعلق TRX على فيلى بعض المض

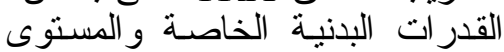

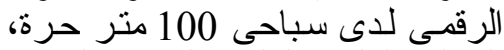

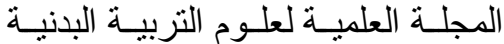
و علوم الرياضة، كلية التربية الرياضية لئية

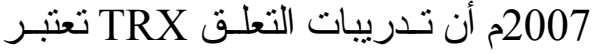

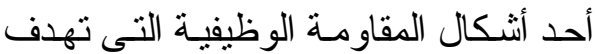

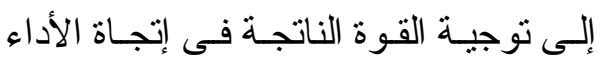

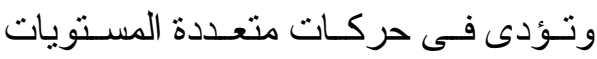

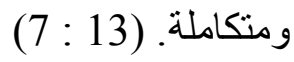
الاستنتاجات: 1- البرنـامج التدريبى المقتر ح المطبق لـه

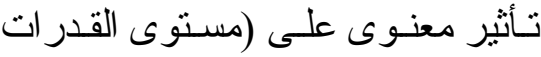
البدنية الخاصة

2- البرنـامج التدريبى المقتر ح المطبق لـه

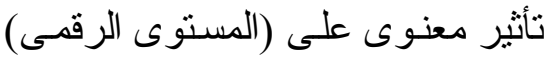

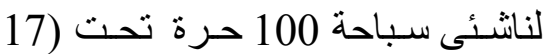
سنة). 3- البرنامج التدريبى المقتر ح خطوة نحو

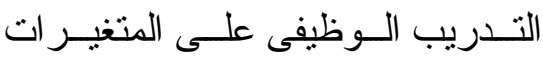
البدنية وذلك لمـا يحتويه على تدريبات الـيه

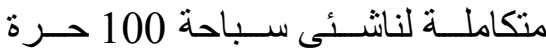
تحت (17 سنة). 2/5 التوصيات:

1- ضـرورة الإهتمــام باسـتخدام تـدريبات TRX \& Vipr

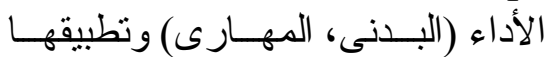

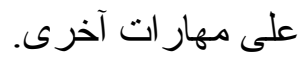
2- إجــر اء در اســات تســتخدم تــدريبات TRX \& Vipr السنية المختلفة (بنين - بنات).

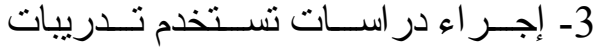
TRX \& Vipr أخرى. 4- وضع نتائج الدر اسـة فى الاعتبـار عند

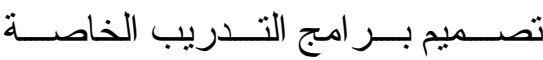
بتدريبات TRX \& Vipr. 
Využití TRX v tréninku juda,:

Bakalářská práce, masarykova univerzita, Fakulta sportovních studií, Brno, 2014.: Martin

Tůma

TRX: make your body your machine, CPT, MP, 503 d MP Bn (ABn) TF Ripcord, FOB Lightning, Afghanistan, 2010.: Michael Miranda

Application of TRX: and RIP training to the development of strength endurance in tennis, ITF Coaching and Sport Science Review, 11 November 2012.

Jordi Martínez, Carlos Beltrán, Iván Alcalá, Richard Gonzalez TRX make your body your machine, CPT, MP, 503 d MP Bn (ABn) TF Ripcord, FOB Lightning, Afghanistan, 2010.

Michael Miranda: Effects of Instability versus Traditional Resistance Training on Strength, Power and Velocity in Untrained Men, Journal of Sports Science and Medicine, 468, 13-460, 2014.

José Luis: Maté-Muñoz, Antonio J. Monroy Antón, Pablo Jodra Jiménez, Manuel V. Garnacho-CastañoVyužití

TRX v tréninku juda, Bakalářská

masarykova práce, Fakulta sportovních studií, Brno, 2014.

Martin Tůma: Využití TRX v thajském boxu, Bakalárská

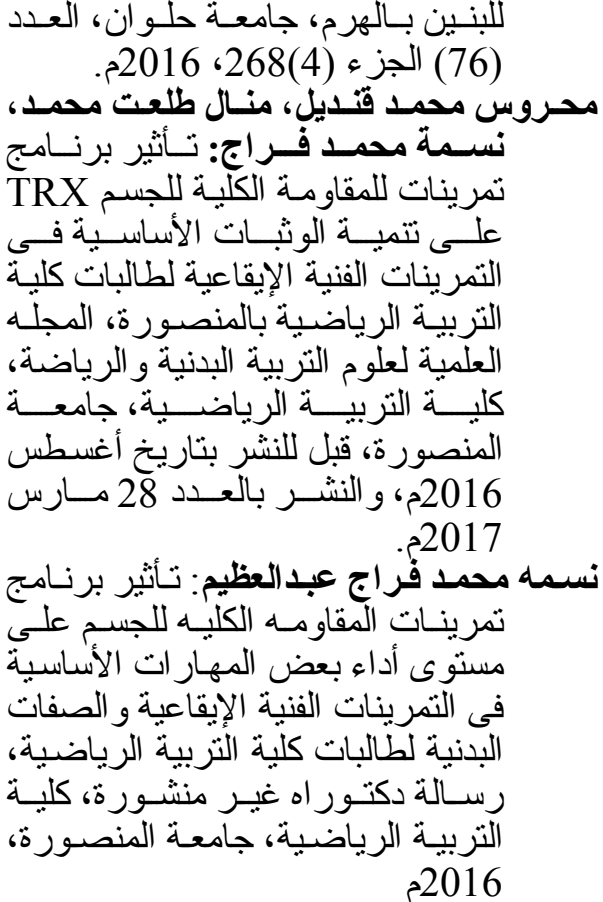

Physiologic and Metabolic: Effects of a Suspension Training Workout, International Journal of Sports Science, 5 (2): 65-72, 2015: Wesley

D. Dudgeon, Judith M. Herron, Johannas A. Aartun, David D. Thomas, Elizabeth P. Kelley, Timothy P. Scheett

TRX (Závesný trénink), Diplomová masarykova univerzita, Fakulta sportovních studií, Brno, 2010.: Bc. Martin Hajnovič

Využití TRX- závesného: tréninku $\mathrm{u}$ hráce ledního hokeje, Bakalárská práce, masarykova univerzita, Fakulta sportovních studií, Brno, 2011.: Lukáš Sláma 


\section{Department of Sports}

Therapy, university College Birmingham, U.K., 2010.

Sukhjivan SinghIan: lahart‘Paul RobertsonEffect of TRX Training Module on Legs Strength and Endurance of Females, $\mathrm{M} \quad \mathrm{R}$ INTERNATIONAL JOURNAL OF APPLIED HEALTH SCIENCES, October 2015.

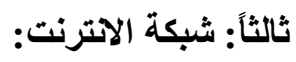

http://varzeshvasalamat.persianblo g.ir/post/18/,1391

$\mathrm{http} / / /$ suspensiontrainingaustralia.c om.au/2012/index.php?optio $\mathrm{n}=\mathrm{com}$ cont

ent\&view $=$ article\&id $=1 \&$ Itemid $=1$ 32

$\mathrm{http}: / /$ seattlehealthandfitness.blogs pot.com/2010/07/what-isTRX-suspensiontraining.html

http://www.menshealth.com.sg/fitn ess/get-started-vipr

http://www.viprfit.com/Introducin gViPR/TeamViPR/MicholD alcourt.aspx

http://furthermore.equinox.com/art icles/2013/03/vipr-workout http://createfit.com/articales/benefi ts-viper-training práce, univerzita, masarykova sportovních studií, Brno, 2014.

Vojtech

DvorákTRX: SUSPENSION TRAINING METHOD AND STATIC BALANCE IN JUNIOR BASKETBALL PLAYERS, STUDIA UNIVERSITATIS BABEs-BOLYAI EDUCATIO ARTIS GYMNASTICAE, ROMANIA, pp. 27-34. LX, 3., 2015.

BOROS-BALINT: IULIANA, DEAK GRAȚIELAFLAVIA‘MU $\square$ AT

SIMONA, PĂTRA $\square \mathrm{CU}$ ADRIANEffects Of Angle Variations In Suspension Push-Up Exercise, National Strength \& Conditioning Association, March 3, 2016

Gulmez,: IrfanThe design of a judo-specific strength and conditioning programmer, $\mathrm{http}: / /$ suspensiontrainingaustralia.c om.au/2012/index.php?optio $\mathrm{n}=\mathrm{com}$ cont

ent\&view $=$ article $\& \mathrm{id}=1 \&$ Itemid $=1$ 32

http://www.calgaryherald.com/heal th/resistance + training + tool $+\mathrm{i}$ mproves + trend + toward + movement + training/ 8789539/story.html

http://www.rmhp.org/blog/2013/01 /30-minute-workout-withthe-vipr 